\title{
O DIREITO AO ENSINO DE QUALIDADE: REPRESENTAÇÕES SOCIAIS DE UMA COMUNIDADE
}

\author{
BORBA, Valdinéa Rodrigues de Souza ${ }^{1}$ \\ DINALLI, $\mathrm{A}^{2}$
}

Recebido em: 2008-02-13

Aprovado em: 2009-04-25

ISSUE DOI: $10.3738 / 1982.2278 .168$

\begin{abstract}
RESUMO: Esta pesquisa identifica e analisa as representações sociais dos docentes, dos discentes e dos pais sobre a escola de tempo integral e o direito ao ensino de qualidade. Parte dos pressupostos de que a garantia do direito público subjetivo à educação é constitucional; a escola de tempo integral possibilita um ensino de melhor qualidade; as representações da equipe gestora, dos docentes, discentes e pais sobre o tema, influenciam as práticas pedagógicas; a participação da família no processo educacional dos filhos, bem como o envolvimento dos discentes em seu processo de aprendizagem, garantem a qualidade do ensino. Neste sentido, o Direito Educacional, Moscovici e Jodelet trazem contribuições importantes. A metodologia, de cunho qualitativo, utiliza como instrumentos a associação livre de palavras, questionário semi-estruturado, análise documental, entrevista, diário de campo e pesquisa bibliográfica. A análise e interpretação dos dados apontam para a afirmação de que o Direito Constitucional Educacional ao ensino de qualidade é entendido como um fato real na escola de tempo integral, apesar de o tempo de permanência do aluno na escola não ser uma condição sine qua non para a garantia deste direito, tampouco para o sucesso escolar. Mostra também que para os pais o mais importante é a permanência da criança na escola, pois lá podem ter uma alimentação equilibrada e ficar distantes dos perigos que a rua oferece. Estas concepções contribuem para a discussão sobre o papel de toda a comunidade escolar na busca pela qualidade do ensino e na garantia de direitos educacionais inerentes ao cidadão.
\end{abstract}

Palavras-chave: Direito público subjetivo à Educação. Direito ao ensino de qualidade. Escola de Tempo Integral. Representações Sociais. Direito Educacional.

\section{THE RIGHT TO EDUCATION QUALITY: SOCIAL REPRESENTATIONS OF A COMMUNITY}

SUMMARY: This research identifies and analyzes the social representations of teachers, the students and parents about full-time school and the right to education of quality. Part of the assumptions that the security of subjective public right to education is constitutional; the full-time school allows an education of better quality; the representations of management team, teachers, students and parents about the issue, influencing the practices teaching; the family's participation in the educational process of children, as well as the involvement of students in their learning process, ensure the quality of teaching in schools. Accordingly, the Education Law, Moscovici and Jodelet bring significant contributions. The guiding methodology of this study gives a stamp of quality and uses as tools for data collection to free association of words, semi-structured questionnaire, document analysis, interviews, diary of field and literature search. The analysis and interpretation of data point to the assertion that the Constitutional Education Law to the teaching quality is understood by children, teachers and parents investigated as a fact in full-time school, although the stay of students in school is not a sine qua non for the security of this law, nor for success in school. Also shows that for parents the more important is access and permanence of children in school, because then you can have a balanced diet and staying away from the dangers that the street offers. These approaches contribute on the discussion about the role of the whole school community in the search for the quality of education and ensuring educational rights that are inherent to the citizen.

\footnotetext{
1 Mestre em Educação. Especialista em Direito Educacional.

Doutora em Direito, Consultora em Direito Educacional, Membro da Comissão de Direitos Humanos da $12^{\mathrm{a}}$ Subseção da OAB de Ribeirão Preto
} 
Keywords: Right to Education subjective public. Right to education of quality. School Integration time. Social Representations. Educational Law.

\section{INTRODUÇÃO}

Esta pesquisa identifica e analisa as representações sociais dos gestores, docentes, discentes e dos pais sobre a Escola de Tempo Integral (ETI) e o direito ao ensino de qualidade. Objetiva verificar também se a permanência na escola o dia todo (por 9 horas) é entendida pela comunidade escolar como uma possibilidade de garantir um ensino de melhor qualidade aos estudantes, ou seja, analisar se os direitos fundamentais dos alunos quanto à educação de qualidade estão sendo garantidos nesta escola.

Parte dos pressupostos de que a garantia do direito público subjetivo à educação é constitucional e que a escola de tempo integral possibilita um ensino de melhor qualidade. Entende que as representações dos sujeitos sobre o tema, influenciam as práticas pedagógicas.

O referencial teórico fundamenta-se em ordenamentos jurídicos referentes à Educação e em autores como Dinalli e Paro que trazem reflexões, respectivamente, sobre o Direito Educacional e a Escola de Tempo Integral. Dialoga ainda com Moscovici e Jodelet, na tentativa de delinear as implicações pedagógicas decorrentes dos aspectos estudados à luz da Teoria das Representações Sociais.

\section{Direito à Educação, Qualidade do Ensino e Teoria das Representações Sociais}

No Estatuto da Criança e do Adolescente - ECA (Lei 8069, de 1990), na Lei de Diretrizes e Bases da Educação Nacional - LDB (Lei 9394, de 1996) e no Plano Nacional de Educação (Lei 10.172, de 2001), estão presentes as idéias de educação integral e de educação de tempo integral, entendida como ampliação da jornada escolar.

Especificamente quanto à Educação, o ECA determina, in verbis: “A criança e o adolescente têm direito à educação, visando ao pleno desenvolvimento de sua pessoa, preparo para o exercício da cidadania e qualificação para o trabalho.” (Lei 8069/1990, Artigo 53). Defende a ampliação da formação de crianças e adolescentes promovida através da destinação de espaços adequados e recursos para programações de lazer, culturais e esportivas. 
A LDB, em seu artigo 34, parágrafo 2, aponta que, in verbis: "O ensino fundamental será ministrado progressivamente em tempo integral, a critério dos sistemas de ensino." (BRASIL, 1996). Tem como princípio e fim a garantia do padrão de qualidade do ensino.

Por sua vez, o Plano Nacional de Educação (PNE - Lei n 10.162, de 9/01/2001) incentiva o investimento na permanência e no sucesso escolar dos estudantes e ressalta os resultados positivos da jornada em tempo integral. In verbis: "O atendimento em tempo integral [...] é um avanço significativo para diminuir as desigualdades sociais e ampliar democraticamente as oportunidades de aprendizagem." (BRASIL, 2001)

Assim, no estado de São Paulo, o projeto Escola de Tempo Integral (ETI) foi instituído na rede pública de ensino, através da Resolução SE 89, de 9/12/2005, que estabelece, in verbis, "[...] ampliar as possibilidades de aprendizagem, com o enriquecimento do currículo básico, a exploração de temas transversais e a vivência de situações que favoreçam o aprimoramento pessoal, social e cultural." (SÃO PAULO, SEE, 2005)

Dessa forma, a ETI significa muito mais que uma simples ampliação da jornada escolar, pois representa uma proposta pedagógica que tem como intenção questionar a própria escola e sua função social. Nela a questão do tempo escolar não pode ser pensada apenas como uma extensão do tempo que o estudante fica na escola, pois “[...] resulta em aumento da oferta de condições e possibilidades para a realização de uma proposta que se pretende redimensionada no seu sentido educacional." (SÃO PAULO, 2007, p. 9). Isso implica em melhorar a qualidade do ensino, o que vai ao encontro da determinação constitucional.

Vale ressaltar que a Educação deve ser priorizada como um direito decorrente de norma, já estabelecida, que apresenta caráter público e, além disso, subjetivo. A noção de Direito Subjetivo "indica a possibilidade ou capacidade de cada um agir de acordo com o direito, isto é, dentro da lei e de pedir a sua proteção e aplicação na defesa de seus interesses, sempre que for necessário." (DINALLI, 2008a, p. 5). Assim, tendo sido configurada a Educação como um direito público subjetivo, através da Constituição Federal de 1988, os brasileiros têm o direito de requerer ao Estado a prestação deste serviço, e a autoridade competente para oferecê-la pode ser responsabilizada se não cumprir a determinação legal.

O PNE e a Década da Educação, preconizados pela Lei 9.394/96 (LDB), enfatizam a busca de soluções para os problemas da educação brasileira, com prioridade 
no Ensino Fundamental e no atendimento à diversidade humana, ou seja, buscando construir uma escola inclusiva. (DINALLI, 2008a). Nesse sentido, "o direito à educação se exerce na medida em que as pessoas, além de terem acesso à escola, possam desenvolver-se plenamente e continuar aprendendo. Isso significa que a educação terá de ser de qualidade para todos e por toda a vida." (BRASIL, 2002).

Vale lembrar, que a família também é responsável pela educação de seus filhos, ou seja, a educação “[...] como direito de todo cidadão é dever não só do Estado como também da sociedade, e principalmente da família, de acordo com o disposto no artigo 55 do ECA [...]” (DINALLI, 2008b, p. 29). Visto sob esse ângulo, a educação garantirá o pleno desenvolvimento da pessoa, assegurando-lhe uma série de direitos que serão viabilizados através do acesso do sujeito ao conhecimento e à informação.

Assim, à medida que a pessoa vai conhecendo mais, vai se informando sobre o que acontece no mundo todo, ela desenvolve representações, tentando ajustar-se a ele. $\mathrm{Na}$ busca de dominá-lo física e intelectualmente, vai identificando e resolvendo os problemas que se apresentam e dessa forma, tentando superar os obstáculos, ou seja, vai criando representações sociais. A esse processo Moscovici denomina Teoria das Representações Sociais (TRS).

A TRS foi desenvolvida, em 1961, por Serge Moscovici, partindo do pressuposto de que as representações sociais, ou seja, as idéias das pessoas são formadas a partir dos grupos sociais, ou seja, do coletivo. Para ele, a representação social é: “[...] é um corpus organizado de conhecimentos e uma das atividades psíquicas graças às quais os homens tornam inteligível a realidade física e social, inserem-se num grupo [...]" (MOSCOVICI, 1978, p.28)

Corroborando esta afirmação, Jodelet (2001) defende que a Teoria das Representações Sociais aborda como pontos fundamentais a atividade do sujeito e a realidade do mundo "[...] é uma forma de conhecimento, socialmente elaborada e partilhada, com um objetivo prático, e que contribui para a construção de uma realidade comum a um conjunto social." (p. 22). Argumenta que as representações sociais necessitam ser analisadas “[...] articulando-se elementos afetivos, mentais e sociais e integrando - ao lado da cognição, da linguagem e da comunicação - a consideração das relações sociais que afetam as representações e a realidade material, social e ideativa sobre a qual elas têm de intervir." (Ibidem, p. 26)

As representações sociais devem ser estudadas articulando-se elementos afetivos, mentais e sociais e integrando - ao lado da cognição, da linguagem e da 
comunicação - a consideração das relações sociais que afetam as representações e a realidade material, social e ideativa sobre a qual elas têm de intervir (Ibidem, p. 26).

Nessa perspectiva, os indivíduos ou grupos sociais partilham de uma mesma definição sobre um objeto por eles representado, construindo uma visão consensual da realidade.

\section{METODOLOGIA}

Esta investigação apresenta uma abordagem de cunho qualitativo (TRIVIÑOS, 1987; MINAYO, 2001), foi realizada em uma escola pública de tempo integral do interior do Estado de São Paulo e pesquisou as concepções da comunidade escolar sobre o direito à educação de qualidade. Foram investigados 105 sujeitos, entre alunos de $4^{\mathrm{a}}$ série do Ensino Fundamental (49 crianças), seus respectivos pais/responsáveis (49 adultos), gestores (3) e professoras (4).

Como procedimentos e instrumentos para coleta de dados, foram utilizados:

- Associação livre de palavras: Termo indutor: "Escola de Tempo Integral".

- Aplicação de questionário: para identificar as concepções dos gestores, docentes e pais/responsáveis sobre o direito à educação.

- $\quad$ Entrevista com as crianças: cujas respostas foram gravadas e transcritas.

- $\quad$ Análise documental: Planos de Ensino e Projeto Político Pedagógico.

- Diário de campo: anotações, reflexões da pesquisadora e transcrições de respostas.

\section{DISCUSSÃO DOS DADOS}

Analisando os dados coletados foi possível elencar as seguintes categorias:

- Representações Sociais sobre a ETI (Escola de Tempo Integral): A ETI é entendida pelos sujeitos investigados como: revisão e reforço de aprendizagem; agradável, pois as crianças gostam de estudar em tempo integral; chance de estudar e aprender mais; útil muito mais para fins sociais que pedagógicos.

Verificou-se que a equipe gestora e docente da escola está bastante esclarecida quanto às principais finalidades da escola de tempo integral. Contudo, enfatizam muito mais que o ideal a questão da revisão e reforço de aprendizagem nas aulas regulares e oficinas curriculares. Pode ser que a equipe gestora t enha sido influenciada pelo 
discurso da comunidade que entende a escola como muito mais útil para fins sociais que pedagógicos.

- Representações sociais acerca do direito público subjetivo à educação: Direito à educação como garantia de acesso à escola; de permanência na escola; como obrigação do estado; como garantia de qualidade no ensino; forma de suprir carências sociais.

A esse respeito, Vitor Paro (1988b) adverte que toda escola está sendo vista como uma estratégia para minimizar os efeitos nocivos desencadeados pela estrutura econômica do país, gerando uma lógica excludente. Postula também que a educação integral não deveria ser secundarizada como está acontecendo no país, pois atividades de esporte, arte e cultura são desenvolvidas somente com o intuito de entreter e manter as crianças ocupadas no contra turno do ensino regular oferecido nas escolas de tempo integral.

- Representações sociais a respeito da qualidade do ensino na ETI: Para alguns a condição de ensino em tempo integral não é garantia de qualidade; já para outros, esta condição é garantia de qualidade; alguns creditam a qualidade do ensino à competência do professor e não à quantidade de horas que a criança permanece na escola; e, para outros, a escola de Tempo Integral não é melhor, pois, os alunos se cansam de ter estudar o dia todo.

Sobre este tema, Libâneo (2003) aponta que a promoção da democratização do ensino, requerida de forma constitucional, a busca pela garantia de uma escola pública para todos, com resultados em qualidade, é fundamental para a efetivação o direito de fato ao pleno exercício da cidadania. E o pleno exercício da cidadania é condição essencial para a conquista de uma sociedade mais justa e democrática.

De acordo com Paro (1988a) é preciso que a escola de tempo integral desenvolva no educando a consciência de ser social e coletiva que lhe é inerente, pois a partir daí, este poderá superar sua deficiência econômica.

\section{- Representações sociais e a garantia de direitos expressos em documentos oficiais} da escola: realizou-se a análise de documentos oficiais da escola, os Planos de Ensino das docentes e do Projeto Político Pedagógico da escola. Verificou-se que, de fato, o direito do aluno a ter acesso e permanecer numa escola de tempo integral cujo ensino seja qualidade é uma máxima defendida e citada várias vezes nestes documentos.

Contudo, numa escola onde cotidianamente, na prática e na materialização das representações sociais, os atores principais do processo apostam numa instituição 
escolar que serve preferencialmente para atender às necessidades fisiológicas dos alunos, os resultados quanto à qualidade do ensino não podem ser atendidas a contento. E isso pode ser verificado nos resultados do Plano de Qualidade da Escola - IDESP: Índice de Desenvolvimento da Educação do Estado de São Paulo, referentes ao ano de 2007 (SÃO PAULO, IDESP 2007).

De acordo com estes dados do Idesp, a escola investigada ficou abaixo dos índices alcançados, em média, pelas escolas da rede pública estadual da grande São Paulo, do interior do estado, bem como da própria região (Diretoria de Ensino) e do município da qual ela faz parte. Dessa forma, têm-se o atendimento à Constituição Federal, à LDB e outras legislações conexas, apenas no tocante ao acesso e permanência na escola e não no que diz respeito à qualidade do ensino ofertado. Nesse sentido, a "construção de uma cidadania plena requer que o direito a ter direitos saia da teoria e integre a prática de uma vida com dignidade, em uma sociedade onde possamos ser menos desiguais nas nossas igualdades.” (DINALLI, 2005, p. 9)

Dessa forma, pode-se verificar que as representações sociais dos sujeitos sobre os temas investigados podem ter influenciado sua maneira de pensar, de forma a interferir em suas práticas do dia-a-dia, conforme advoga Moscovici (1978; 1985), mesmo que esse processo pareça acontecer de forma inconsciente nos envolvidos.

\section{CONSIDERAÇÕES FINAIS}

A análise de dados permitiu concluir que, as representações sociais dos investigados sobre a escola de tempo integral e o direito à educação de qualidade influenciam suas ações práticas no dia a dia da escola, tornando-a uma instituição com muitos ideais redigidos nos documentos oficiais da escola, mas com poucos resultados satisfatórios. Conseguem ser bem aceitos pela comunidade que pouco exige em termos de qualidade, pois estão preocupados, em sua maioria, com o assistencialismo social oferecido por ela, que a seu ver, é bom. Os profissionais parecem vendados quanto à forma de transformar em resultados o que está posto no Plano de Ensino e no Projeto Político Pedagógico da escola. Atendem parcialmente à comunidade em seus objetivos sociais, contudo fracassam na questão pedagógica.

É fato que a criança hoje tem buscado e, muitas vezes, encontrado na escola, o seu principal espaço de construção de conhecimentos, elaboração de valores, acesso à cultura e à informação, à prática de lazer, socialização e até mesmo de alimentação. 
Essa demanda social faz-se mais presente e visível na ETI, destinada às classes menos favorecidas, o que reforça a necessidade de reflexões constantes sobre a proposta e filosofia da escola, ou seja, a equipe deve pensar sobre que tipo de homem quer formar e qual está formando.

Assim, é necessária a garantia do acesso e permanência na escola, mas acima de tudo, com resultados, pois, não basta se preocupar apenas com o tempo escolar, mas também com o desenvolvimento integral dos alunos, com a integração e contextualização dos conteúdos.

Faz-se importante ressaltar o papel fundamental que representam as discussões e reflexões promovidas pelos próprios professores sobre suas práticas pedagógicas. Estas podem ocorrer em reuniões de estudos ou nos encontros de HTPC (Horário de Trabalho Pedagógico Coletivo), realizados nas escolas semanalmente e dos quais também participam os coordenadores pedagógicos. Primordial também é a conscientização dos professores da necessidade de formação continuada em seu percurso profissional.

Outrossim, o tema deve ser objeto de estudo nas faculdades de graduação e formação inicial de docentes. Por conseguinte, o Direito à educação de qualidade deve ser amplamente discutido na academia e também pela sociedade em geral, pois o reconhecimento da importância do saber sistemático para a disseminação da herança cultural da humanidade é determinante para o progresso de qualquer nação.

A educação é o mais relevante problema da democracia brasileira. Definir soluções em uma global governança no epicentro de uma crise econômica internacional requer políticas públicas onde a dignidade e os direitos humanos fundamentais sejam respeitados. Neste momento o Estado deve ser um redutor de inseguranças, de agir global e localmente, de mudar e transformar, de recompor e reassumir o sentido da existência humana, construindo uma cidadania onde possamos viver, morar e produzir em uma sociedade livre, justa e solidária.

\section{REFERÊNCIAS}

BRASIL. Constituição da República Federativa do Brasil. São Paulo: Imprensa Oficial do Estado, 1988. . MEC. Lei de Diretrizes e Bases da Educação Nacional. Lei no 9.394/96. . Lei 10.172, de 9/01/2001. PNE. D.O.U. Brasília, DF, 10 jan. 2001. 
. Constituição da UNESCO. Brasília, fev.2002. Disponível em: http://www.brasilia.unesco.org/areas/educacao/areastematicas/enfundamental/DireitoE D Acesso em: 23 out.2008.

Ministério da Educação e do Desporto. Lei n⿳0 11.274/2006.

DINALLI, Aparecida. Direito Educacional I. Batatais: Ceuclar, 2008a.

Direito Educacional III. Batatais: Ceuclar, 2008b.

et al. Constituição e construção da cidadania. Leme: J.H.Mizuno, 2005.

JODELET, Denise. (org.) As Representações sociais. Rio de Janeiro. Eduerg, 2001.

LIBÂNEO, J. C.; OLIVEIRA, J. F.; TOSHI, M. S.. Educação escolar: políticas, estrutura e organização. São Paulo: Cortez, 2003.

MINAYO, M.C.S. (Org.) Pesquisa social: teoria, método e criatividade. Rio de Janeiro: Vozes, 2001.

MOSCOVICI, S. A representação social da psicanálise. Rio de Janeiro: Zahar, 1978.

Sobre representações sociais. Traduzido por Clélia Nascimento Schulze. Núcleo de Psicologia Social, Departamento de Psicologia, UFSC, 1985.

PARO. Vitor et alii. Escola de tempo integral: desafio para o ensino público. São Paulo: Cortez, 1988a.

A escola pública de tempo integral: universalização do ensino e problemas sociais. Cadernos de Pesquisa, n. 65, 1988b, p. 11-20.

SÃO PAULO (Estado). SEE - Secretaria da Educação. Resolução SE $\mathbf{n}^{\mathbf{0}}$ 89, de 9 de dezembro de 2005. Dispõe sobre o projeto Escola de Tempo Integral.

Secretaria da Educação. CENP. Escola de Tempo Integral: Construção de uma proposta. Ciclos I e II. São Paulo: SEE/CENP, 2007.

Secretaria da Educação. Programa de Qualidade da Escola. IDESP 2007. Disponível em: http://idesp.edunet.sp.gov.br/ Acesso em: 30 out.2008.

TRIVIÑOS, A. N. S. Introdução à pesquisa em ciências sociais: a pesquisa qualitativa em educação. São Paulo: Atlas, 1987. 
